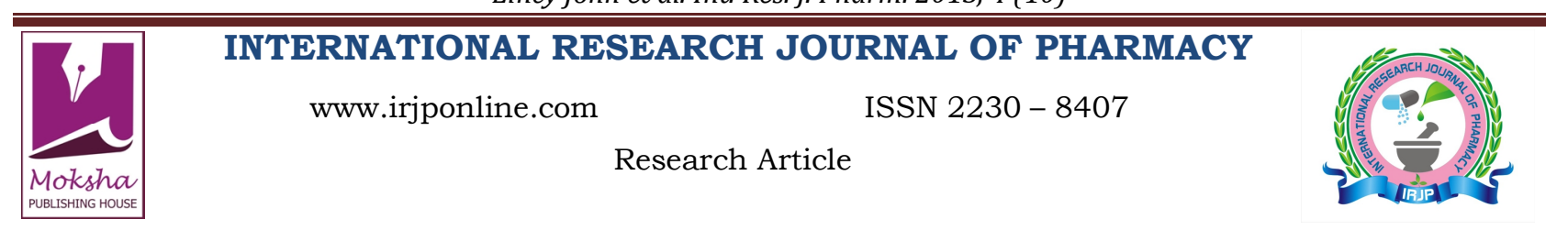

\title{
FORMULATION AND EVALUATION OF AMLODIPINE TRANSDERMAL PATCHES USING ETHYL CELLULOSE
}

Lincy john*, Arun Kumar and Sandra Samuel

Department of Pharmaceutics, KMCH College of Pharmacy, Coimbatore, Tamil Nadu, India

*Corresponding Author Email: lincy.bikaner@gmail.com

Article Received on: 17/08/13 Revised on: 21/09/13 Approved for publication: 20/10/13

DOI: $10.7897 / 2230-8407.041019$

IRJP is an official publication of Moksha Publishing House. Website: www.mokshaph.com

(C) All rights reserved.

\section{ABSTRACT}

The aim of our study was to design and evaluate Amlodipine transdermal patches using polymers such as ethyl cellulose. Matrix type transdermal patches containing Amlodipine were prepared by solvent casting method by using polymers like ethylcellulose $1 \%, 1.5 \%$, $2 \%$ and $2.5 \%$ and a total of eight formulations were prepared. Plasticizers used were propylene glycol and dibutylpthalate. The transdermal patches were evaluated for their physicochemical properties like folding endurance, thickness, percentage moisture loss, percentage moisture absorption, drug content and water vapour transmission rate. The diffusion studies were performed by using franz diffusion cell. Formulation E6 (1.5\% Ethylcellulose with dibutylphthlate) as plasticizers showed a maximum release of $99 \%$ in 24 hours. Out of these eight formulations of EC, $1.5 \%$ Ethylcellulose (E6) was optimized since they produced a sustained and a complete release over a period of 24 hours. Thus the knowledge on the use of ethyl cellulose to control drug release in transdermal delivery systems might be applicable to other transdermal drug delivery system as well.

Keywords: Transdermal, ethylcellulose, Amlodipine

\section{INTRODUCTION}

Delivering medicine to the general circulation through the skin is seen as a desirable alternative to taking it by mouth or by oral route. Transdermal drug delivery is defined as delivering the drug through the skin at controlled rate to the systemic circulation. The transdermal patches uses a polymer membrane to control the rate at which the drug contained in the reservoir within the patch can pass through the skin and into the blood stream ${ }^{1}$. Today most of the drug are taken orally but, they are found not to be as effective as desired, So to improve such character TDDS was emerged. Currently TDDS is one of the most promising methods for drug application. Transdermal drug delivery provides a leading edge over injectables and oral route by increasing patient compliances and avoiding first pass metabolism respectively. TDDS not only provides a controlled, constant administration of drug, but also allows continuous input of drug with short biological half life and eliminates pulsed entry into systemic circulation which often causes undesirable side effect $^{2}$. Transdermal drug delivery provides a leading edge over injectables and oral route by increasing patient compliances and avoiding first pass metabolism respectively. TDDS not only provides a controlled, constant administration of drug, but also provide short biological half life and eliminates pulsed entry into systemic circulation which often causes undesirable side effect ${ }^{3,4}$. The objective of this research work was to develop a transdermal system which can produce a constant and prolonged release of the drug, to evaluate the effect of ethyl cellulose on the fabrication of the patch and drug release from the patch, to evaluate the effect of plasticizers on the physico-chemical properties of the patch and on drug permeation across the membrane.

\section{MATERIALS AND METHODS}

\section{Material}

Amlodipine was kindly supplied as gift samples by Microlabs Pharmaceuticals, Banglore, India. Polymers and plastizier used were purchased by SD fine chemicals, India. The Drug analysis was performed using UV Spectroscopy. In addition, an electronic balance (Shimadzu AX200), magnetic stirrer (REMI model Mumbai), a sonicator (Spectra Lab, model UCB 40), a hot air oven (Labhosp) and a Franz diffusion cell (self fabrication) were used in this study.

\section{Methodology \\ Formulation of Transdermal Drug Delivery System}

TDDS was developed using solvent evaporation method. In this polymer is dissolved in particular solvent and then the specified quantity of drug as well as plasticizers were added and was air dried for $24 \mathrm{~h}$ in petridish with help of inverted funnel for controlled evaporation ${ }^{5,6}$. A total of 8 formulations were made in as shown in Table 1.

\section{Preparation of Amlodipine Patches}

Drug loaded matrix type transdermal films of Amlodipine were prepared by solvent evaporation method. The polymers like EC were dissolved in particular solvents with help of magnetic stirrer followed by the addition of drug into the polymeric solution and then the plasticizers were incorporated with continuous stirring and the volume was made up. The resultant solution was casted onto the petridish and an inverted funnel was placed. After 24 hours the films were removed by using sharp knife by inserting along the edge of the films and stored for further studies ${ }^{7}$.

\section{Evaluation of Transdermal Patches \\ Physical Appearance}

All the prepared patches were visually inspected for color, clarity, flexibility and smoothness ${ }^{8}$.

\section{Thickness Uniformity}

The thickness of the formulated film was measured at 3 different points using a calliper and average thickness was calculated ${ }^{9}$.

\section{Folding Endurance}

The folding endurance was measured manually for the prepared films. A strip of film $1 \mathrm{~cm}^{2}$ was cut and repeatedly 
folded at the same place till it broke. The number of times the film could be folded at the same place without breaking or cracking gives the value of folding endurance ${ }^{10}$.

\section{Percentage Moisture Absorption}

The films were weighed accurately and placed in desiccators containing $100 \mathrm{ml}$ of saturated solution of potassium chloride after 3 days; the films were taken out and weighed. The percentage moisture absorption was calculated using the formula ${ }^{11}$.

$$
\begin{gathered}
\% \text { moisture absorption }=\text { Final weight }- \text { Initial weight } x 100 \\
\text { Initial weight }
\end{gathered}
$$

\section{Percentage Moisture Loss}

The films were weighed accurately and placed in a desiccators containing anhydrous calcium chloride ${ }^{15}$. After 3 days, the films were taken out and weighed. The percentage moisture loss was calculated using the formula given below ${ }^{12}$.

$$
\% \text { moisture loss }=\text { Initial weight }- \text { Final weight } \times 100
$$
Initial weight

\section{Water Vapor Transmission Rate}

Glass vials of $5 \mathrm{ml}$ capacity were washed thoroughly and dried to a constant weight in an oven. About $1 \mathrm{~g}$ of fused calcium chloride was taken in the vials and the polymer films were fixed over the brim with the help of adhesive tape. Then the vials were weighed and stored in a humidity chamber of $70-80 \% \mathrm{RH}$ condition for a period of $24 \mathrm{~h}$. The vials were removed and weighed after $24 \mathrm{~h}$ to note down the weight gain and transmission rate was found out ${ }^{13}$.

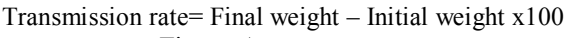

\section{Drug Content}

$1.1544 \mathrm{~cm}^{2}$ areas of the small films were cut and were dissolved in sufficient quantity of methanol. The volume was made up to $100 \mathrm{ml}$. The absorbance of the diluted solution was measured at $238 \mathrm{~nm}$ and the drug content in the film was calculated $^{14}$.

\section{In- vitro Drug Diffusion Studies}

In- vitro diffusion studies were performed by using franz diffusion cell with a receptor compartment capacity of $20 \mathrm{ml}$. The synthetic cellophane membrane was mounted between donor and receptor compartment of the diffusion cell. The formulated patches were cut into size of $1.4 \mathrm{~cm}$ radius and placed over the drug release membrane and the receptor compartment of the diffusion cell was filled with phosphate buffer $\mathrm{pH}$ 7.4. The whole assembly was fixed on a magnetic stirrer, and the solution in the receptor compartment was constantly and continuously stirred using magnetic beads at $50 \mathrm{rpm}$. The sample of $2 \mathrm{ml}$ were withdrawn at time intervals of 30 minutes, $1 \mathrm{~h}, 1.30 \mathrm{~h}, 2 \mathrm{~h}, 3 \mathrm{~h}, 4 \mathrm{~h}, 5 \mathrm{~h}, 6 \mathrm{~h}, 7 \mathrm{~h}, 8 \mathrm{~h}$ and $24 \mathrm{~h}$ and analyzed for drug content spectrophotomerically at $238 \mathrm{~nm}^{15}$.

\section{RESULT}

\section{Calculation of Total Drug Loading}

The formulation of the patch was made in such a way that each small circular patch of $1.4 \mathrm{~cm}$ radius (which is the radius of the franz diffusion cell) contains $5 \mathrm{mg}$ of the drug. The total amount of drug to be loaded in the patch was calculated by measuring the total area of the petri dish in which the patch will be casted. The calculation was done as follows;

$$
\begin{gathered}
\text { Area of the small circular patch }=6.1544 \mathrm{~cm}^{2} \\
\text { Desired drug content in the small patch }=5 \mathrm{mg} \\
\text { Area of the petri dish }=67.89 \mathrm{~cm}^{2} \\
\text { Total amount of drug to be loaded }=67.89 \times 5 / 6.1544=55 \mathrm{mg} \\
\text { Hence } 55 \mathrm{mg} \text { of the drug was added in each formulation in order to get } 5 \mathrm{mg} \\
\text { per small circular patch }
\end{gathered}
$$

\section{Preparation of Transdermal Patches}

As per the methodology transdermal patches using EC were prepared by using solvent casting method.

\section{Evaluation of Prepared Transdermal Patches Folding Endurance}

In general, folding endurance of all the films was found to be satisfactory indicating good strength and elasticity. The observed values are given in Table 2 . Folding endurance of $\mathrm{EC}$ was found to be in the range of 70-80. Folding endurance was found to increase with the polymer content.

\section{Thickness}

Thickness of EC were evaluated with the use of a vernier caliper and was found to be in the range of $0.20-0.25 \mathrm{~mm}$.

\section{Percentage Moisture Loss}

Percentage moisture loss for ethyl cellulose containing patches was found in the range of $2.12-13.68 \%$. Percentage moisture loss of prepared ethyl cellulose patches was found to be increased with increase in the percentage of the polymer $(1 \%, 1.5 \%, 2 \%$ and $2.5 \%)$ irrespective of the plasticizers (DBP and PG) used.

\section{Percentage Moisture Absorption}

Percentage moisture absorption for EC was found in the range of $6.21-10.31 \%$. Percentage moisture absorption tends to decrease with increase in the percentage of EC (1\%, $1.5 \%, 2 \%, 2.5 \%$ ) irrespective of plasticizers (DBP and PG) used.

\section{Water Vapour Transmission Rate}

Water vapour transmission rates for EC was found in the range of $0.189-0.243 \mathrm{~g} / \mathrm{cm}^{2} / \mathrm{h}$. Water vapour transmission rate results were found to be similar to the results obtained in moisture absorption studies.

\section{Drug Content}

Drug content in each small circular patches were analyzed spectrophotmetrically and It was observed that all the formulations showed a satisfactory drug content values ranging from $92-99 \%$.

Table 1: Formulations Containing EC Patches

\begin{tabular}{|c|c|c|c|}
\hline Drug & Polymers & Plasticizers & Polymer Percentage (\%) \\
\hline Amlodipine & Ethyl & DBP & 1 \\
& cellulose & PG & 1.5 \\
& & & 2 \\
& & & 2.5 \\
\hline
\end{tabular}

$\mathrm{EC}=$ Ethylcellulose $; \mathrm{PG}=$ Propyleneglycol $; \mathrm{DBP}=$ Dibutylphthlate 
Table 2: Evaluation of Prepared EC Patches

\begin{tabular}{|c|c|c|c|c|c|}
\hline Formulations & $\begin{array}{c}\text { Folding } \\
\text { Endurance }\end{array}$ & $\begin{array}{l}\text { Thickness } \\
\text { (mm) }\end{array}$ & $\begin{array}{c}\text { Percentage Moisture } \\
\text { loss }(\%)\end{array}$ & $\begin{array}{l}\text { Percentage Moisture } \\
\text { Absorption (\%) }\end{array}$ & $\begin{array}{c}\text { Water Vapor Transmission } \\
\text { Rate }\left(\mathrm{g} / \mathrm{cm}^{2} / \mathrm{h}\right)\end{array}$ \\
\hline E $1(1 \%$ EC and PG) & 72 & 0.21 & 2.12 & 9.31 & 0.2439 \\
\hline E $2(1.5 \%$ EC and PG) & 74 & 0.22 & 8.69 & 6.54 & 0.2345 \\
\hline E 3 (2\% EC and PG) & 75 & 0.23 & 11.36 & 6.59 & 0.2168 \\
\hline E $4(2.5 \%$ EC and PG) & 76 & 0.24 & 11.62 & 5.71 & 0.2019 \\
\hline E 5 (1\% EC and DBP $)$ & 75 & 0.22 & 2.52 & 10.31 & 0.2303 \\
\hline E $6(1.5 \%$ EC and DBP $)$ & 77 & 0.23 & 5.25 & 8.52 & 0.2205 \\
\hline E $7(2 \%$ EC and DBP $)$ & 79 & 0.24 & 6.48 & 7.65 & 0.2032 \\
\hline E $8(2.5 \%$ EC and DBP $)$ & 80 & 0.25 & 13.68 & 6.81 & 0.1897 \\
\hline
\end{tabular}

$\mathrm{EC}=$ Ethylcellulose $; \mathrm{PG}=$ Propyleneglycol $; \mathrm{DBP}=$ Dibutylphthlate

Table 3: Assay and Cumulative drug release of Prepared EC Patches

\begin{tabular}{|c|c|c|c|}
\hline Formulation & Assay (\%) & Cumulative drug release at 8 h (\%) & Cumulative drug release at 24 h (\%) \\
\hline E 1 (1\% EC and PG) & 98.98 & 82.34 & - \\
\hline E 2 $(1.5 \%$ EC and PG) & 98.41 & 61.38 & 72.80 \\
\hline E 3 (2\% EC and PG) & 96.74 & 51.62 & 65.30 \\
\hline E 4 (2.5\% EC and PG) & 97.97 & 32.14 & - \\
\hline E 5 (1 \% EC and DBP) & 92.29 & 85.21 & 99.12 \\
\hline E 6 (1.5\% EC and DBP) & 95.95 & 58.23 & 76.80 \\
\hline E 7 (2\% EC and DBP) & 96.39 & 56.24 & 69.39 \\
\hline E 8 (2.5\% EC and DBP) & 97.97 & 40.12 & \\
\hline
\end{tabular}

$\mathrm{EC}=$ Ethylcellulose $; \mathrm{PG}=$ Propyleneglycol $; \mathrm{DBP}=$ Dibutylphthlate

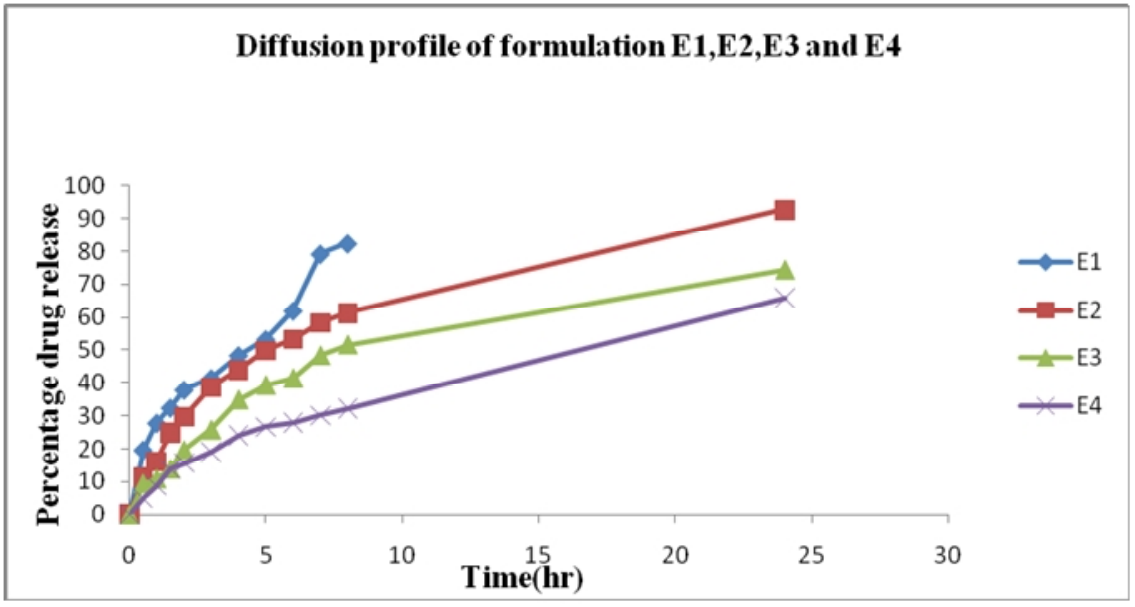

Figure 1: Diffusion study of E1, E2, E3 and E4

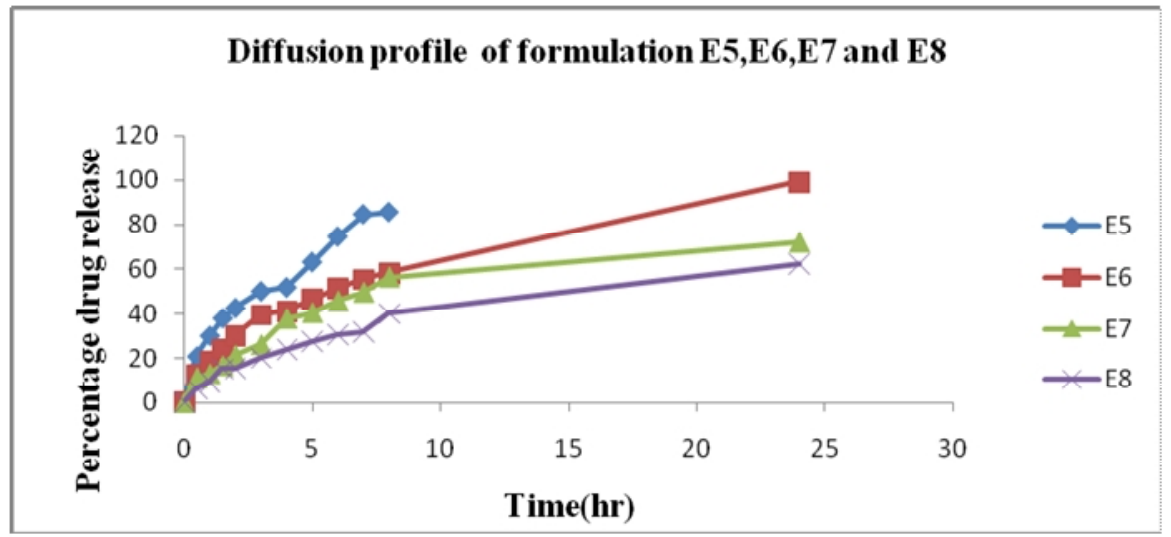

Figure 2: Diffusion study of E5, E6, E7 and E8

\section{Diffusion Study}

Effect of EC Patches on Drug Release

As shown in Table 3, the formulations with $1 \%$ EC with PG and DBP (E1 and E5) as plasticizers showed a maximum release of more than $80 \%$ within 8 hours. The formulation with $1.5 \%$ EC (E2 and E6) showed around a $61.38 \%$ and $58.23 \%$ release at 8 hours and about $92.8 \%$ and $99.12 \%$ release respectively for PG and DBP containing patches at the end of 24 hours. When concentration of EC was further increased to $2 \%$ and $2.5 \%$, the formulations showed the least percentage drug diffusion of just $30-40 \%$ at 8 hours and around $65-75 \%$ at the end of 24 hours. From the above result it was observed that $1.5 \%$ EC containing formulations 
produced a sustained and complete release over a period of 24 hours.

\section{DISCUSSION}

The present study was aimed at preparing transdermal patches containing Amlodipine for sustained release of drug and studies the effect of polymer on rate of release. Since the oral bioavailability of Amlodipine is poor due to first pass metabolism, different matrix type transdermal patches were formulated. Transdermal patches composed of different polymers such EC at different concentration of $1 \%, 1.5 \%, 2$ $\%$ and $2.5 \%$ using two different plasticizers PG, DBP were prepared using solvent casting technique. A total of 8 formulations were made using Ethyl cellulose. The formulated patches were subjected to physicochemical evaluatory parameters i.e. folding endurance, thickness, moisture loss, moisture absorption, water vapour transmission rate and assay to ascertain their integrity and physical stability. Folding endurance value of matrix films were found within $230-310$ no of folds, indicating good strength and elasticity and that the patch would maintain the integrity with general skin folding when applied. The thickness of all the formulations indicates physical uniformity among the prepared patches. The drug content analysis values show minimum batch variability. Hydrophilic polymers like HPMC and CS with increased concentration showed an increase in water vapor transmission rate and \% moisture absorption as it was able to retain water in the patch while hydrophobic polymer like EC with increased concentration showed a decrease value, as it was able to repel water. Optimization of the formulated patches was done by performing in-vitro diffusion rate studies using franz diffusion cell with cellophane membrane. In these studies with the increase in the percentage of the polymer, the \% cumulative release decreases. The decrease in drug release from patches containing EC may be attributed to hydrophobic nature of polymerwhich helps to retain the drug in matrix system by reducing the penetration of solvent molecule into the patch. The formulations with $1 \% \mathrm{EC}$ with PG and DBP (E1 and E5) as plasticizers showed a maximum release of more than $80 \%$ within 8 hours which suggest that these formulation were not able to sustain the drug release for a desired time. The formulation with $1.5 \%$ EC (E2 and E6) showed around a $61.38 \%$ and $58.23 \%$ release at 8 hours and about $92.8 \%$ and $99.12 \%$ release respectively for PG and DBP containing patches at the end of 24 hours. When concentration of EC was further increased to $2 \%$ and $2.5 \%$, the formulations showed the least percentage drug diffusion of just $30-40 \%$ at 8 hours and around $65-75 \%$ at the end of 24 hours. From the above result it was observed that $1.5 \%$ EC containing formulations were found to be more suitable since they produced a sustained and complete release over a period of 24 hours. Among the two different plasticizers used with these formulations, DBP seems to be better with respect to physical properties as well as drug release characterstics. DBP containing patches showed an increase in drug diffusion of about $85.21 \%, 58.23 \%, 56.24 \%$ and $40.12 \%$ for $1 \%$, $1.5 \%, 2 \%$ and $2.5 \%$ as compared to percentage of PG with same content of EC. Thus the formulation E6 with $1.5 \%$ EC and DBP as plasticizer was considered as best among EC containing formulations.

\section{CONCLUSION}

Delivery of drug into systemic circulation through skin has created lot of interest among pharmaceutical scientist during recent years. The transdermal system offers several advantages over oral dosage forms which include avoidance of hepatic first pass effect metabolism, decrease in frequency of administration, providing steady state plasma concentration and improves patient compliance etc. Hence in this study an attempt was made to deliver Amlodipine transdermally in order to provide a constant serum level of drug over the prolonged period of time. Polymers like EC were selected for the study and were used at different concentrations. PG and DBP were incorporated as plasticizers in the formulations. On evaluation of various parameters it was found that the polymers produced satisfactory results with respect to the physical characteristics of the film and the release characteristics across synthetic membrane. The release profile suggested that increase in polymer content led to decrease in release rate of the drug. Lower concentration of polymers gave an initial burst release of about $50 \%$ within 2 hours and as concentration were increased they were able to sustained the release for prolonged period but could not release the entire content in the prescribed time limit. Hence it was concluded that concentration of $1.5 \%$ for EC with DBP (E6) as plasticizers will be the most suitable one for the transdermal systems of Amlodipine as it showed sustained and complete release at a period of 24 hours. Further studies using various animal models can throw more light on the variability of the prepared transdermal systems.

\section{ACKNOWLEDGEMENT}

The authors are thankful to the staff and management of kovai medical college, Coimbatore, India for providing all the facilities to accomplish my research work.

\section{REFERENCES}

1. Bhowmik D, Chiranjib, Margret C, Jayakar B, Sampath KP. Recent Advances in Transdermal Drug Delivery System: International Journal of Pharmaceutical. Technology and Research 2010; 2(1): 68-77.

2. Guru S, Biplab K, Nagarajan K, Sujit D, Vijaykumar. S, Dinesh.V. Effect of permeation enhancer on propanolol hydrochloride formulated patches: International Journal Of pharmaceutical science 2010; 2(2): 2131 .

3. Gaur P, Mishra S, Purohit S, Dave K. Transdermal drug delivery system a review: Asian Journal of pharmaceutical and Clinical Research 2009; 2(1): 14-19.

4. Jitendra B, Subhash P, Pathak A. Formulation and evaluation of matrix type transdermal system of Lisinopril dehydrate using permeation enhancers: Journal of pharmaceutical research 2008; 1(1): 16-21.

5. Hemangi J, Jitendra S, Desai B, Keyur D. Design and evaluation of Amlodipine besilate transdermal patches containing film former: International Journal of pharmaceutical research and development 2009; 7(001): 1- 12 .

6. Jadhav RT, Gattani SG, Surana SJ. Formulation and evaluation of transdermal films of diclofenac sodium: International Journal of pharmaceutical Technology and Research 2009; 1(4): 1508-1511.

7. Murthy TEGK, Kishore VS. Effect of casting solvent on permeability of antihypertensive drugs through ethyl cellulose films: Journal of pharmaceutical science 2008; 67(2): 147-150.

8. Murthy TEGK and Kishore VS. Effect of casting solvent and polymer on permeability of propranolol hydrochloride through membrane controlled transdermal drug delivery system: Indian Journal of Pharmaceutical Science 2007; 69(5): 646-650. http://dx.doi.org /10.4103/0250-474X.38469

9. Subramanian K, Sathyapriya LS, Jayaprakash S, Prabhu RS, Abirami A, Madhumitha B et al. An Approach to the formulation and evaluation of transdermal DDS of isoxsuprine $\mathrm{HCl}$ : International Journal of Pharmaceutical. Science and Technology 2008; 1(1): 8 - 22.

10. Shinde AJ, Garala KC, More HN, Development and characterization of transdermal therapeutics system of tramadol hydrochloride: Asian Journal of Pharmaceutics 2008; 2(4): 265-269. http://dx.doi.org/ 10.4103/0973-8398.45044

11. Pandit V, Khanum A, Bhaskaran S, Banu V. Formulation and evaluation of transdermal films for the treatment of overactive bladder: International. Journal of Pharmaceutical Technology and Research 2009; 1(3): 799-804. 
12. Rao V, Mamatha T, Mukkanti $\mathrm{K}$ and Ramesh. Transdermal drug delivery system for atomoxetine hydrochloride- in vitro and ex vivo evaluation: Current. Trends in Biotechnology and Pharmacy 2009; 3(2): $96-188$.

13. Satturwar PM, Fulzele SV, Dorle AK. Evaluation of polymerized rosin for the formulation and development of transdermal drug delivery system: A Technical Note: Journal of membrane science 2005; 6(4): 649 -654 .

14. RK Kar, S Mohapatra, BB Barik. Design and Characterization of Controlled Release Matrix Tablets of Lamivudine: Asian Journal of Pharmaceutical and Clinical Research 2009; 2(2): 212-220.
15. Beny B, Abin A, Ramesh K, Rajarajan S. Design of transdermal patches of ketorolac tromethamine and its In vitro drug release studies. Journal of pharmaceutical research 2009; 2(3): 357-362.

Cite this article as:

Lincy john, Arun Kumar and Sandra Samuel. Formulation and evaluation of Amlodipine transdermal patches using ethyl cellulose. Int. Res. J. Pharm. 2013; 4(10):84-88 http://dx.doi.org/10.7897/2230-8407.041019

Source of support: Nil, Conflict of interest: None Declared 